\title{
Circulating vaccine-derived poliovirus: a menace to the end game of polio eradication
}

\author{
Long Chiau Ming ${ }^{*^{*}}$ (D), Zahid Hussain ${ }^{2}$, Siang Fei Yeoh ${ }^{3}$, David Koh ${ }^{1,4}$ and Kah Seng Lee ${ }^{5}$
}

\begin{abstract}
The World Health Organisation Western Pacific Region countries were declared free of polio in 2000 until a polio outbreak involving 305 cases occurred in Indonesia in 2006. It was not until 2014 that the World Health Organisation South East Asia region was officially declared polio-free again. However, in February 2019, the Global Polio Eradication Initiative announced a new circulating vaccine-derived poliovirus outbreak in the Papua province of Indonesia. To make matter worse, the outbreak responses were tardy and led to transmission among migrating communities to other cities. The pressing regional issues of polio outbreak caused by circulating vaccine-derived poliovirus and use of oral polio vaccine have not been well presented. Our letter highlighted the suboptimal outbreak responses as well as the necessity of cross-border vaccination to curb continued poliovirus transmission.
\end{abstract}

Keywords: Immunization, Vaccination, Poliomyelitis, Vaccine supply and distribution, Vaccine control, oral polio vaccine, inactivated polio vaccine

Until recently, there had been no reported cases of polio since 1978 in Brunei [1], since 1992 in Malaysia and since 1993 in the Philippines [2]. The World Health Organization (WHO) Western Pacific Region countries were declared free of polio in 2000 until a polio outbreak involving 305 cases occurred in Indonesia in 2006 [3]. However, in 2019, polio re-emerged in three countries in the Western Pacific region. The Global Polio Eradication Initiative announced a new circulating vaccinederived poliovirus (cVDPV) outbreak in Papua, Indonesia in Feb 2019. In September 2019, a national polio outbreak was declared in the Philippines [4]. Subsequently, on December 6, 2019, the WHO's Polio Regional Laboratory in Australia verified that the sample taken from an infant from the Malaysia Borneo state of Sabah was infected with cVDPV which had a direct link

\footnotetext{
* Correspondence: long.ming@ubd.edu.bn

'PAP Rashidah Sa'adatul Bolkiah Institute of Health Sciences, Universiti Brunei Darussalam, Jalan Tungku Link, Gadong BE1410, Brunei Darussalam

Full list of author information is available at the end of the article
}

to the polio virus detected in the acute flaccid paralysis cases reported in the neighboring Filipino island of Mindanao [4].

\section{Main cause of re-emergence \\ cVDPV remains a menace to the end game of polio eradication as it is one of the main causes of re- emerging polio apart from vaccination refusal. cVDPV originates from the oral polio vaccine. This weakened virus is excreted by the body through feces which could spread easily in a non-sanitary environment. In the early 2000s, in order to avoid the risk of cVDPV posed by the weakened poliovirus transmitted through oral polio vac- cine (OPV), inactivated polio vaccine (IPV) was strongly advocated. By June 2018, 39 of 47 African countries had changed from OPV to IPV. In spite of that, sporadic cases of cVDPVs were spotted in countries using OPV with low population immunity [5]. For example, in 2018, cVDPV outbreaks were reported in Nigeria, Kenya and the Democratic Republic of the Congo,}


Another approach to totally eliminate the risk of reemergence of wild poliovirus type-2, is to utilize bivalent OPV that contains Sabin serotypes 1 and 3 strains, instead of trivalent OPV that contains Sabin strains of all three poliovirus serotypes [6].\{Regional Committee for Africa (68), 2018 \#6\} Drastic measures were taken when all member states in the WHO African Region withdrew trivalent OPV in May 2016 [5]. In Southeast Asia, Brunei and Malaysia has fully utilized the IPV but the trivalent OPV is still used in the Philippines and Indonesia with the latter introducing IPV in the national immunization program from July 2016 [7]. Furthermore, the use of monovalent type- 2 polio vaccine in response to cVDPV Type- 2 outbreaks poses the risk of the emergence of "de-novo" cVDPV Type-2 [8].

Besides the use of IPV or bivalent OPV, a comprehensive vaccine coverage is essential. Even though in general Brunei and Malaysia had achieved more than 95\% immunization rates, approximately $12 \%$ of the children living in the affected sites on the coastal region of Sabah were not vaccinated, putting the whole community at risk of losing the vital herd immunity. The situation is heterogenous as across the South China Sea, the immunization rate among 105 million residents in the Philippines stood at 66 and $41 \%$ for OPV and IPV, respectively [9]. In the remote Papua province of Indonesia, polio vaccination coverage was $68.2 \%$ in 2017 and $40.8 \%$ in 2018 [10].

\section{Cross-border polio vaccinations: the urgent need in southeast Asian countries}

Cross border cooperation and efforts are needed. The mapping of less accessible border areas e.g. in Papua New Guinea and Timor Leste as well as migrant routes is important. The vaccination should be given by humanitarian groups to stateless children or non-citizens. It is especially important to maintain coverage of polio immunization at over $95 \%$ in high-risk areas with seasonal migrant populations. Surveillance of vaccination patterns based on data mining and geo-mapping of migrant and cross-border vaccinations that has proven successful in containing polio in Nigeria could be adopted to optimize the limited vaccine stocks and healthcare resources.

\section{Conclusion}

The health authorities need to increase the inactivated polio vaccine coverage to prevent further spread of cVDPV. Doctors should always look out for polio-like symptoms of acute flaccid paralysis among children by testing the presence of polio virus or cVDPV in the patients' stool samples. Other important precautionary measure is to test the presence of polio virus or cVDPV at sewage treatment plants. Application of advanced analytics and disease transmission model to map out and estimate seasonal migrant routes and populations could save time and lives of the vulnerable populations. Despite of inactivated polio vaccine stock-outs and cost of polio vaccination, cross-border vaccination at permanent transit point and surveillance of nomadic populations would still be cost-effective. The existence of inadequately vaccinated groups within neighbouring countries pose a serious threat to reintroduction of the poliovirus.

\section{Abbreviations \\ OPV: Oral polio vaccine; IPV: Inactivated polio vaccine; CVDPV: Circulating vaccine-derived poliovirus; WHO: World Health Organization}

\section{Acknowledgements \\ None.}

Authors' contributions

Conceived the conceptual framework: LCM. Wrote the paper: LCM, ZH, DK. Designed search strategies: LCM, SFY, KSL. Critically reviewed the manuscript for important intellectual content: DK, KSL. All authors read and approved the final version.

Funding

None.

Availability of data and materials

All data have been included.

Ethics approval and consent to participate

Not applicable.

Consent for publication

Not applicable.

Competing interests

We declare no competing interests.

\section{Author details}

${ }^{1}$ PAP Rashidah Sa'adatul Bolkiah Institute of Health Sciences, Universiti Brunei Darussalam, Jalan Tungku Link, Gadong BE1410, Brunei Darussalam.

${ }^{2}$ Discipline of Pharmacy, School of Health Sciences, Faculty of Health,

University of Canberra, Canberra, Australia. ${ }^{3}$ Department of Pharmacy, National Hospital Health System, Singapore, Singapore. ${ }^{4} \mathrm{SSH}$ School of Public Health, National University of Singapore, Singapore, Singapore. ${ }^{5}$ Faculty of Pharmacy, University of Cyberjaya, Cyberjaya, Selangor, Malaysia.

Received: 15 February 2020 Accepted: 6 July 2020

Published online: 16 July 2020

\section{References}

1. Ministry of Health Brunei Darussalam. Polio Outbreak in Laos. Available online: http://www.kesihatan.gov.bn/Lists/Latest\%20news/NewDispForm. aspx? ID=30\&ContentTypeld= 0x0104009A3003A09F8D6E42981D262E322516A2. Accessed 20 December 2019. 2019.

2. International Federation of Red Cross And Red Crescent Societies. Philippines: Polio Outbreak Emergency Plan of Action (EPOA) DREF n⿳ MDRP H035. Available online: https://reliefweb.int/report/philippines/philippinespolio-outbreak-emergency-plan-action-epoa-dref-n-mdrph035. Accessed 28 December 2019. 2019.

3. Outbreaknewstoday. Polio in Indonesia: 1st case in over a decade (15 February 2019). Available online: http://outbreaknewstoday.com/polioindonesia-1st-case-decade-72885/. Accessed 28 December 2019. 2019.

4. Reliefweb. Philippines/Malaysia: Polio Outbreak - Sep 2019. Available online: https://reliefweb.int/disaster/ep-2019-000110-phl. Accessed 28 December 2019. 2019. 
5. Regional Committee for Africa (68). Framework for certification of polio eradication in the African Region: Report of the Secretariat. World Health Organization. Regional Office for Africa. https://apps.who.int/iris/handle/1 0665/275135. 2018.

6. Centers for Disease Control and Prevention. Global Certification of Eradication of Indigenous Wild Poliovirus Type 3. Available online: https:// www.cdc.gov/globalhealth/immunization/stories/global-certification-oferadication-of-indigenous-wild-poliovirus-type-3.html. Accessed 28 December 2019. 2019.

7. WHO Indonesia. The Switch of OPV Replacing trivalent OPV (tOPV) with bivalent OPV (bOPV). Available online: http://origin.searo.who.int/indonesia/ topics/immunization/switch_tOPV_bOPV/en/. Accessed 28 December 2019. 2019.

8. Al-Mazrou Y. Report from the Polio WG Meeting (9-10 February, 2017): SAGE Polio Working Group. Available from: https://www.who.int/ immunization/sage/meetings/2017/april/AI_Mazrou_Polio_SAGE_WG_ SAGE_Apr2017.pdf?ua=1. Accessed 28 December 2019; 2017.

9. World Health Organization. Polio outbreak - The Philippines: Disease outbreak news, 24 September 2019. Available online: https://reliefweb.int/ report/philippines/polio-outbreak-philippines-disease-outbreak-news-24september-2019. Accessed 26 December 2019. 2019.

10. World Health Organization. Circulating vaccine-derived poliovirus type $1-$ Indonesia. Available online: https://www.who.int/csr/don/27-february-2019polio-indonesia/en/. Accessed 28 December 2019. 2019.

\section{Publisher's Note}

Springer Nature remains neutral with regard to jurisdictional claims in published maps and institutional affiliations.

Ready to submit your research? Choose BMC and benefit from:

- fast, convenient online submission

- thorough peer review by experienced researchers in your field

- rapid publication on acceptance

- support for research data, including large and complex data types

- gold Open Access which fosters wider collaboration and increased citations

- maximum visibility for your research: over $100 \mathrm{M}$ website views per year

At $\mathrm{BMC}$, research is always in progress.

Learn more biomedcentral.com/submissions 